\title{
Do Oiapoque ao Chuí - As escolas civis militarizadas: a experiência no extremo norte do Brasil e o neoconservadorismo da sociedade brasileira
}

\author{
From Oiapoque to Chuí - The militarized civilian schools: the experience in the \\ far north of Brazil and the neoconservatism of brazilian society \\ De Oiapoque a Chuí - Las escuelas civiles militarizadas: la experiencia en el \\ extremo norte de Brasil y el neoconservadurismo de la sociedad brasileña
}

ADALBERTO CARVALHO RIBEIRO

PATRÍCIA SILVA RUBINI

\begin{abstract}
Resumo: O objetivo é refletir sobre as razões do aceite social do novo modelo de gestão militar em escolas civis mostrando o ritual em determinada unidade localizada no norte do Brasil. A abordagem metodológica é qualitativa com estudos na literatura, consultas a sítios jornalísticos e pesquisa empírica com observações in loco, conversas informais e entrevista referentes a experiência situada no Amapá. O método de análise dos instrumentos de campo foi análise do discurso. Os resultados apontam que não há nenhuma novidade no modelo de escolas civis cuja gestão passou a ser feita por militares. É a velha Pedagogia Bancária que retira do aluno o protagonismo. Estamos diante de uma das facetas neoconservadoras em andamento no Brasil.
\end{abstract}

Palavras-chave: Escolas civis militarizadas; Positivismo; Neoconservadorismo.

Abstract: The objective is to reflect on the reasons for the social acceptance of the new model of military management in civil schools showing the ritual in a particular unit, located in northern Brazil. The methodological approach is qualitative with studies in the literature, consultations with journalistic sites and empirical research with in loco observations, informal conversations, and interviews regarding the experience in Amapá. The method of field instrument analysis was discourse analysis. The results show that there is nothing new in the model of civilian schools that is now managed by the military. It is the old banking pedagogy that removes the protagonism of the student. We are facing one of the neoconservative facets in progress in Brazil.

Keywords: Militarized civilian schools; Positivism; Neoconservatism. 


\begin{abstract}
Resumen: El objetivo es reflexionar sobre los motivos de la aceptación social del nuevo modelo de gestión militar en las escuelas civiles demostrando el ritual en una determinada unidad ubicada en el norte de Brasil. El enfoque metodológico es cualitativo con estudios en la literatura, consultas a sitios periodísticos e investigación empírica con observaciones in situ, conversaciones informales y entrevistas sobre la experiencia ubicada en Amapá. El método de análisis de instrumentos de campo fue el análisis del discurso. Los resultados muestran que no hay nada nuevo en el modelo de escuelas civiles que cuya gestión ahora es hecha por los militares. Es la vieja Pedagogía Bancaria la que elimina el protagonismo del alumno. Nos enfrentamos a una de las facetas neoconservadoras en progreso en Brasil.
\end{abstract}

Palabras clave: Escuelas civiles militarizadas; Positivismo; Neoconservadurismo.

\title{
INTRODUÇÃO
}

Este trabalho reflete questões advindas da intervenção de órgãos estatais, como a Polícia Militar (PM), na organização administrativa e pedagógica de escolas públicas civis, particularmente no estado do Amapá,. Centralmente, pretendemos refletir sobre as razões pelas quais se deu o aceite e o apelo social para a implantação desse 'novo' modelo de gestão, tido, no plano local amapaense, como uma gestão militar compartilhada. Também vamos mostrar o ritual militar - especialmente quanto ao controle de condutas e comportamentos, imposição de disciplina, hierarquias e valores morais - implementados em determinada escola pesquisada, que está localizada na periferia da cidade de Macapá, estado do Amapá, no extremo norte do Brasil.

A preocupação da pesquisa está ligada principalmente a dois fatores: o primeiro é a transferência de responsabilidade da família quanto à educação moral, ética e social dos filhos, uma vez que existem fortes indícios de que as famílias atuais não conseguem mais controlar seus filhos porque teriam perdido a autoridade moral sobre eles.

O segundo fator, está voltado à suposta incapacidade de gestão escolar dos civis para a obtenção de desempenhos escolares satisfatórios, uma vez que os resultados das avaliações nacionais revelam desempenhos muito ruins dos alunos, especialmente nas escolas de periferia.

É como se os dois fatores estivessem apontando para a falência de duas instituições basilares da sociedade: a família e a escola ${ }^{1}$. Sem conseguir conter

\footnotetext{
1 Não qualquer escola. Na análise aqui empreendida se trata da escola pública, gratuita, laica e de qualidade, ainda que neste último quesito, como se sabe, no Brasil haja assimetrias abissais. Não obstante, o modelo dos Institutos Federais de Educação não deixa dúvidas o quanto é possível avançar com o sistema público de ensino no país rumo à educação de qualidade. Ou seja, os educadores brasileiros conhecem o caminho para a "eficácia” e qualidade da educação nacional.
} 
as brutais mudanças que a sociedade passou a sofrer na virada do século XX para o XXI, sem conseguir dar conta da suposta inversão de valores que teria reconfigurado as relações sociais, as famílias passaram a concordar com a presença de militares (dos Srs. e Sras. de farda), e até a apelar por ela, nas instituições públicas civis de ensino.

Nessa perspectiva, as questões que norteiam este trabalho são: que razões explicam o aceite e o apelo social para a implantação de escolas civis cuja gestão é feita por militares? Em quais bases teórico-pedagógicas pode-se enquadrar o 'novo' modelo de gestão dessas unidades escolares? Quais evidências estão manifestas no modelo que se alastra pelo país, especialmente no caso empírico do estado do Amapá, que podem apontar para um modelo neoconservador de educação? É possível afirmar que o perfil do jovem formado no modelo de gestão militar compartilhada é de um cidadão acrítico?

A metodologia consiste em abordagem qualitativa. Fizeram-se estudos na literatura optando-se, teoricamente, pelo Positivismo, como teoria que pode explicar o modelo educacional de escolas civis de gestão militar, mas também investigamos sítios jornalísticos que divulgam o debate social atual sobre o tema, mostrando vários posicionamentos desde intelectuais, militares, autoridades parlamentares, órgãos de fiscalização da sociedade, até as posições de pais de alunos.

Realizamos pesquisa empírica com observações, conversas informais e anotações em caderno de campo referentes à experiência de determinada unidade escolar situada no estado do Amapá. Durante duas semanas, observações e conversas informais, especialmente com monitores, foram registradas no caderno de campo. Foi entrevistado o Diretor Adjunto da unidade pesquisada, cujo cargo militar é de Tenente. O método de análise da entrevista e das conversas informais foi baseado na análise do discurso.

No Brasil, a novidade 'escola civil de gestão militar' ocorre com mais força no estado de Goiás, onde o modelo, até agora, mais avançou em termos quantitativos dentre todas as unidades federadas. Foi no ano de 2013 que os termos de acordos foram assinados, autorizados, e em 2014 as primeiras implementações desse novo tipo de escola ${ }^{2}$ foram realizadas.

No estado do Amapá a implantação é mais recente e data do ano de 2017. Por enquanto, três escolas civis estão funcionando sob a gestão de militares mas com a perspectiva de o número ser aumentado.

2 Novo porque, na verdade, é apenas um modelo híbrido, fugindo às características especificas de colégios propriamente militares, bem como da natureza de escolas públicas civis. Assim, a presença de militares, e ainda mais na gestão, é uma novidade que faz parte de um momento da sociedade brasileira que embarcou de modo mais amplo na onda neoconservadora global. Como veremos, nos aspectos centrais, o modelo é velho conhecido. 
No Rio Grande do Sul, existem os clássicos colégios militares e também a rede de colégio Tiradentes vinculada às forças armadas. Todavia, a Assembleia Legislativa criou uma frente parlamentar para fomentar a implantação do modelo naquele estado com previsão de se iniciar no ano de 2020.

Transformar escolas públicas civis em locais controlados por militares, na perspectiva de formar cidadãos passivos é um dos motivos pelos quais o Ministério da Educação (MEC) apoia e fomenta as iniciativas. Segundo os defensores deste tipo de escola, a disciplina, o respeito à ordem, dentre outros atributos, e a valorização da meritocracia ajudarão positivamente os alunos nos seus desempenhos escolares.

Apesar do 'novo' modelo ser bem recente no Brasil, sabemos que a teoria que pode explicar esse tipo de filosofia de educação é o Positivismo. Fizemos o escrutínio analítico sobre os fundamentos da teoria para comprovar seus vínculos com uma pedagogia (neo) conservadora, 'impositora', domesticadora, como é a natureza dos processos ensino-aprendizagem em corporações militares. O melhor interlocutor para o diálogo só poderia ser Émile Durkheim.

Este trabalho está dividido em cinco seções, incluindo esta introdução. Na seção 2 fazemos um breve histórico do surgimento das escolas civis de gestão militar, revelando que princípios constitucionais, como gestão democrática, estão sendo atacados e que a res pública educacional pode ser engolida por ideais do campo econômico-ideológico neoliberal quando se transfere a responsabilidade para com a educação pública para sistemas exógenos, ferindo de modo flagrante a autonomia institucional das unidades escolares brasileiras.

Na seção 3 descrevemos o caso do estado do Amapá, no extremo norte do Brasil, onde as escolas civis de gestão militar também vêm avançando. A partir de pesquisa de campo, revelamos a rotina à qual os alunos e alunas são submetidos, os códigos comportamentais e de condutas impostos, o controle e a fiscalização das pessoas em nome da ordem e da hierarquia, o ritual diário militar para enquadramento pedagógico, inclusive em relação à linguagem corporal dos alunos e alunas, processos para valorização da competição baseada no mérito, nos prêmios e nos castigos, admoestações e punições, conforme o caso, enfim, o desenho institucional ritualístico da unidade escolar pesquisada.

Na seção 4, nossa preocupação foi comprovar o pano de fundo teórico da escola civil de gestão militar. Aqui, analisamos a teoria positivista, seus principais fundamentos e argumentos em defesa de uma sociedade conservadora e a utilização do sistema educacional para formar pessoas que possam aceitar as regras sociais sem sequer questionar as razões das desigualdades estruturais da sociedade atual. Finalmente, na seção 5, à guisa de conclusão, procuramos retomar nossos objetivos e, em síntese, mostrar os principais achados. 


\title{
EDUCAÇÃO NO BRASIL E O SURGIMENTO DAS ESCOLAS CIVIS DE GESTÃO MILITAR: O VIÉS IDEOLÓGICO CONSERVADOR
}

Como se sabe, muitas são as reformas pelas quais o sistema educacional brasileiro vem passando, especialmente desde a década de 1990. Guimarães (2017) acredita que, no Brasil, essa nova gestão escolar de caráter militar surgiu em decorrência de um processo de expansão do sistema educacional, mas sem o devido investimento educacional, notabilizando-se nas últimas décadas a péssima qualidade da educação pública nacional. Embora o ensino fundamental esteja universalizado no país e passos importantes tenham sido dados para o acesso e a permanência no ensino médio, esse nível de ensino apresenta sérios problemas de distorção idade-série, de reprovação e evasão ainda bastante graves, por exemplo. Segundo ele, desde a década de 1990, a reforma educacional

\begin{abstract}
Nada mais foi do que o cumprimento de uma agenda internacional 'recomendada' por países desenvolvidos, e consistia no cumprimento de uma série de exigências em que países em desenvolvimento teriam que executar uma reestruturação política e econômica para se alinharem ao capital globalizado. (GUIMARÃES, 2017, p.8)
\end{abstract}

Isso explicaria a ideia de "falência do Estado" e por meio do Plano Diretor da Reforma do Estado Brasileiro implementado a partir do ano de 1995 no governo de Fernando Henrique Cardoso (FHC), buscou-se, portanto, realizar a transferência de atividades que eram de responsabilidade do poder público, por exemplo, às entidades sociais conhecidas como Organizações Sociais (OS).

Na perspectiva acima, não demorou para a tese do "apagão educacional" ser disseminada. Conforme Guimarães e Lamos (2018, p. 72-73),

\footnotetext{
A tese de que a escola pública projetada na transição do regime ditatorial para a democracia havia fracassado, tornou-se a principal justificativa para a emergência de novos modelos de gestão do trabalho escolar inseridos nos sistemas estaduais e municipais de ensino.
}

Desse modo, é possível inferir que a proposta de militarização das escolas públicas civis no Brasil encaixa-se também nesse contexto de transferência de responsabilidades da educação pública, gratuita, laica, e sobretudo autônoma, quando se faz uma intervenção por meio de órgãos militares atingindo os próprios princípios constitucionais que garantem a liberdade democrática, a gestão democrática, no sistema educacional brasileiro. 
São os acordos firmados entre Secretarias de Estado de Educação e Secretarias Estaduais de Segurança Pública que preveem que escolas civis sejam administradas pela PM. No estado de Goiás, por exemplo, as funções de comando que determinam as tomadas de decisão estão restritas aos militares e, de acordo com Guimarães e Lamos (2018, p. 75),

Na distribuição dos cargos e das responsabilidades dentro da esfera estatal, constatamos que existe uma distribuição hierárquica a ser seguida. E, de acordo com o Regimento Interno, os cargos de chefia estão concentrados dentro da esfera da Polícia Militar, cuja função é designar os funcionários civis cedidos pela Secretaria de Estado de Educação (SEDUCE) através do Termo de Cooperação.

Para Benevides e Soares (2015, p. 8) "escolas de ensino médio com um viés militarizado ou que são diretamente geridas por militares existem há bastante tempo em diversos países." Todavia, os autores argumentam que essa militarização de escolas civis, nos moldes atuais, é uma novidade, ideia com a qual já concordamos acima, razão pela qual o estamos chamando de 'novo'.

Utilizando novamente o estado de Goiás como exemplo, lá, o modelo foi fortemente implantado e expandido em escolas públicas civis, mas nas de "Periferia, com altos índices de homicídios e com baixos índices de aproveitamento no Exame Nacional do Ensino Médio (ENEM).” (GUIMARÃES, 2017, p. 4).

Com efeito, possivelmente um dos motivos relacionados à aceitação social dessas escolas civis de gestão militar é a divulgação que se tem realizado através da mídia nacional e mostrada na televisão. Assim, Guimarães (2017, p. 10) infere,

Sobre as escolas, colocando a questão da violência como pano de fundo e mostrando a melhora significativa do desempenho dos alunos nos exames nacionais demonstrando claramente que os aparelhos privados de hegemonia estão altamente comprometidos com o projeto político hegemônico do Estado; na difusão e na criação de um consenso.

Uma das características institucionais desse modelo é que as escolas públicas civis de caráter militar não têm a mesma finalidade de um colégio militar no sentido estrito, visto que não preparam os alunos para ocuparem cargos militares, nem mesmo para serem policiais (Guimarães e Lamos, 2018), embora, no estado do Amapá, haja um fenômeno aparentemente se manifestando (em decorrência da ausência de um colégio militar no estado) e que no momento oportuno vamos abordar. 
Outra característica que diferencia o novo modelo de um típico colégio militar é que apenas a gestão institucional da escola (financeira, tomada de decisões e definições da rotina escolar) é feita por militares; a presença de civis (de professores e coordenadores pedagógicos e pessoal de apoio) é em grande maioria disponibilizada pelas secretarias de educação, porém submetendo os profissionais ao regulamento militar. Em outras palavras, as secretarias de educação vêm delegando poderes de gestão administrativa, financeira e pedagógica nas escolas civis aos militares. Na prática, é isso que está ocorrendo.

Entretanto, existem muitas semelhanças com os típicos colégios militares, principalmente quanto à manutenção da hierarquia e às normatizações a serem seguidas pelos alunos e demais atores que fazem parte da comunidade escolar. Por exemplo, a prática disciplinar exercida não atinge apenas os estudos; ela é corroborada com atividades extraescolares. Por isso, essas escolas tiveram aporte de recursos em infraestrutura, a fim de incrementar a prática do esporte, que passa a ser mais um dos mecanismos disciplinares, de hierarquia e de competição, tudo, sob o argumento da meritocracia.

Segundo Benevides e Soares (2015), a disciplina das escolas militares é uma característica fortemente marcante, o que faltaria, ao que parece, nas escolas civis segundo a percepção da sociedade. Os autores destacam que existem regras que devem ser seguidas, como: "O corte de cabelo, a proibição ao uso de adornos e maquiagem usada pelas alunas, entre várias outras normas.” (p. 6). Desse modo, os alunos e seus pais devem conhecer o regulamento da escola de gestão militar logo que matricularem seus filhos e, inclusive, ter consciência das penalidades disciplinares - graduadas em faltas leves, médias e graves - que fazem parte da instituição.

Das inferências acima, pode-se perguntar: o que estaria permitindo o novo modelo ser tão atrativo aos pais dos alunos? Uma possível resposta, além das já reveladas acima, é a mudança ocorrida no escopo da família, que deixou de ser aquela tradicional em que havia o temor reverencial (particularmente em relação ao pai provedor) para se transformar em uma família democrática, com papeis divididos entre homens e mulheres de forma mais democrática e horizontal (a autonomia e o empoderamento das mulheres, por exemplo) transforando-se também em espaço onde o amor entre pais e filhos passou a circular sem as barreiras anteriores. É possível que hoje os pais se sintam, portanto, impotentes, diante das "liberalidades" do mundo moderno das redes sociais e, sem a autoridade (ou autoritarismo) de antes, clamam por uma escola do passado, onde a ordem, o respeito, a moral impunham regras para os mais jovens, experiência essa, inclusive, de que boa parte dos pais é fruto. Talvez, eles esperem de uma escola militar que a disciplina imposta torne os filhos também mais obedientes em casa. 
Desse modo, a proposta dessa nova gestão militar acaba por resgatar um saudosismo do passado quanto ao controle que pais ou responsáveis tinham sobre os adolescentes e jovens, quando as noções de disciplina e respeito, moral e cívica, eram tidas (equivocadamente, a nosso ver) como responsáveis pela melhoria de comportamentos juvenis infringentes. Objetivamente, entrementes, a promessa de diminuição da violência nas escolas, a não entrada de drogas ilícitas e seu consumo dentro ou fora da unidade escolar, o controle de práticas de condutas e comportamentos indesejáveis como das relações intimas, chamaram a atenção não só dos pais, da sociedade, como também dos próprios professores, que passaram a sentir-se mais seguros com o conjunto de possibilidades que a presença da farda militar pode garantir.

Outro possível fator a ser levado em consideração é que a disciplina imposta e a cobrança pelos militares tendem a melhorar o desempenho escolar dos alunos, uma vez que os pais tendem a associar uma coisa à outra esperando que os filhos se tornem alunos mais apegados aos estudos.

O avanço do novo modelo é inquestionável, como ressaltam Guimarães e Lamos (2018); só no estado de Goiás, no ano de 2014, já se alcançava o total de 27 escolas civis militarizadas, quantitativo que aumentou para 47 escolas em 2016, caracterizando, assim, o "sucesso" dessa novidade.

O debate em torno do tema ganhou destaque porque são diversos os interesses em jogo. A coordenadora do Comitê no Distrito Federal da Campanha Nacional pelo Direito à Educação, Catarina de Almeida Santos, referiu-se ao processo de militarização das escolas civis como uma inversão da lógica porque se privilegia-a segurança pública em detrimento da educação. (REDAÇÃO RBA, 2019).

Em artigo publicado pela Revista Época, de autoria de Camporez (2018), a matéria traz relatos, entre eles, de um pai de aluno de escola militarizada de Goiás, que apoia o modelo e elogia a disciplina; ele diz: "Os alunos ficam bem enquadrados. Outros colégios não cobram o respeito familiar, respeito à bandeira do país, à pátria".

Noutro artigo, publicado no Jornal Opção no ano de 2015, cuja autoria é de Marcelo Gouveia, uma mãe de aluno também de escola pública civil militarizada em Goiás, comentou a respeito

Acho que o colégio militar tem mais disciplina, tem mais organização. Hoje, o que nós vemos são alunos desrespeitando professor. Por isso acho que o aluno precisa saber que existe uma ordem. Conheço pessoas com filhos que estudaram em colégios militares e que gostaram muito do ensino. Inclusive, em Brasília, tem filhos de colegas que passaram até para medicina. 
Os relatos acima apontam para a força que têm as questões morais e para o apelo dos pais, preocupados que estão. Esses discursos de apoiadores se amparam também na esperança de que o novo modelo melhore o desempenho dos alunos nas avaliações nacionais pois acreditam ser mais eficaz do que os resultados atuais (insatisfatórios de modo geral) das escolas públicas civis. Assim, uma onda neoconservadora vem tomando conta do debate a respeito da eficácia do ensino público brasileiro, creditando exclusivamente aos profissionais da educação a culpa pelas mazelas do sistema de ensino nacional.

Com efeito, a implantação de escolas civis de gestão militar, segundo o site Nova Escola, em reportagem de Ana Rachel Ferreira (idem), já alcançou 120 escolas em todo o Brasil. As chances desses números aumentarem são cada vez maiores uma vez que o governo federal é um dos maiores incentivadores e criou até uma subsecretaria de Fomento às Escolas Cívico-Militares (SECIM).

Ainda de acordo com Ana Rachel Ferreira da Nova Escola a escolha de unidades escolares que podem receber o modelo "cívico-militar", deve atender a alguns critérios:

Baixo desempenho no Índice de Desenvolvimento da Educação Básica (Ideb), localização em áreas de alta vulnerabilidade social, dentre outros. Para participar do programa deverá haver a adesão das secretarias de Educação, o aceite da comunidade escolar e a disponibilidade de militares em cada localidade.

Como se nota, há intenção e esperança de que a novidade consiga melhorar os índices do IDEB das escolas civis agora militarizadas. Porém, alguns problemas de "exclusão" de determinados grupos de alunos já ficaram evidenciados na operacionalização do modelo militarizado, como por exemplo: 1) reserva de vagas para filhos de policiais militares variando em torno de $50 \%$, e 2) custos cobertos pelos pais com os uniformes escolares. Ainda há relatos de cobranças de taxas mensais. Ora, se a escolha se volta para escola de periferias, cujo público alvo são alunos de camadas populares, as decisões tomadas pela gestão militar estão em desacordo com as possibilidades reais de atender a população do bairro. Com isso, um fenômeno começa a se desenhar em torno do debate: a tendência de "elitização"’3 das escolas civis de gestão militar localizadas na periferia. Elas estão recebendo cada vez mais um público de classe média como os filhos de militares, de professores, de funcionários públicos e etc., que tendem a valorizar mais o capital escolar, entendendo que as chances das notas de seus filhos melhorarem passam a ser maiores. 
Em que pesem as questões acima, o modelo ora analisado ganha força e visibilidade, mas gerando críticas e diferentes opiniões, pois, conforme Picarelli (2019, p.02) em reportagem para a revista Educação,

A tese que sustenta o modelo de escolas cívico-militares é a de que a divisão de responsabilidades da gestão entre militares (cuidando da administração e da disciplina) e os educadores, responsabilizando-se pelas questões pedagógicas, promove a pacificação das escolas, estimulando, de maneira indireta, a melhoria da aprendizagem.

Telma Vinha, professora da Universidade Estadual de Campinas (Unicamp) entrevistada por Picarelli (2019, p. 02) dá a seguinte contribuição

Concordamos que os professores não podem ensinar e os alunos não podem aprender em um ambiente permissivo, com altos níveis de incivilidades, disrupção, indisciplina. Contudo, em nome da busca pela disciplina, está sendo proposta como alternativa a adoção de um ambiente militarizado coercitivo, que traz consigo a violência simbólica.

É exatamente o que está acontecendo, a nosso ver, com essa política educacional híbrida, e com o beneplácito de autoridades educacionais das três esferas públicas brasileiras.

No Rio Grande do Sul (RS), foi criada a Frente Parlamentar das Escolas Cívico-Militares pela Assembleia Legislativa tendo como principal liderança o Deputado estadual Tenente-Coronel Zucco, autor do projeto de lei (PL) 72/2019 que trata da "implantação de escolas cívico-militares no Rio Grande do Sul" e que propõe a adesão de oficiais da reserva das Forças Armadas e da Brigada Militar para exercerem as funções de monitores em escolas públicas, a partir de convênios firmados com as prefeituras. Esses militares realizarão atividades externas à sala de aula, atuando preventivamente na identificação de problemas que possam influenciar o aprendizado e a convivência social do cidadão. O Deputado estadual esteve em Brasília e comemorou os resultados obtidos junto ao Palácio do Planalto e à Esplanada dos Ministérios por ter conseguido viabilizar o que ele chama de "Projeto Escolas Cívico-Militares". Recebeu do Ministro da Educação, Abraham Weintraub, apoio, como também a promessa de que as escolas gaúchas serão modelos. Inicialmente, serão criadas duas escolas-piloto no RS.

O parlamentar considera uma inovação, porque já existem colégios militares em Porto Alegre e em Santa Maria, e alguns colégios Tiradentes da Brigada Militar, todavia, no modelo de escola cívico-militar, não existe uma sequer. No Jornal do Comércio, segundo o parlamentar declarou: 
É uma inovação, o governo federal está apoiando, e a gente pretende, realmente, que o Rio Grande do Sul seja contemplado com uma dezena de escolas. Já tem o interesse de algumas cidades, como Santa Maria, Lajeado, Bagé, Alegrete, Bento Gonçalves, entre outras que também querem instalar esse novo modelo de escola.

O tema, entretanto, não é pacífico e tem gerado a manifestação inclusive de algumas autoridades e instituições que defendem a sociedade. Em 02 de agosto do ano de 2019, o Ministério Público Federal (MPF) do estado da Bahia recomendou aos prefeitos e diretores de escolas civis públicas de gestão militar que se "abstenham de violar ou restringir a intimidade e vida privada dos alunos". (JORNAL GAZETA DO POVO, 2019).

As publicações dos alunos nas redes sociais, afirma o MPF, não devem ser controladas pelos servidores civis ou militares. Ele também aconselha que os estudantes não sejam impedidos de participar de manifestações "de qualquer tipo, sejam políticas ou reivindicatórias, dentro ou fora da escola, fardados ou não".

Ao Comando da Polícia Militar do Estado da Bahia, o MPF ainda recomendou que

Se abstenha, imediatamente, de firmar ou colocar em execução novos acordos que resultem na aplicação da metodologia dos Colégios da PM em escolas públicas municipais nos termos em que vem sendo feito, por incompatibilidade com a Constituição Federal, convenções internacionais, leis e resoluções do Conselho Nacional da Educação, além de importar em violações múltiplas de direitos fundamentais de crianças e adolescentes. (JORNAL GAZETA DO POVO, 2019)

A questão, portanto, além de não ser pacífica, vem enfrentando resistência de setores da sociedade brasileira: a Academia tem realizado boas e duras críticas; intelectuais de diversos matizes também têm criticado o modelo; vozes, ainda que individuais, de professores têm reverberado pelas redes sociais; órgãos de controle e de defesa da sociedade, como o MPF, estão fiscalizando e defendendo os direitos constitucionais. Temos, portanto, uma questão a enfrentar com bons argumentos e revelando que esta não é a saída para os problemas educacionais brasileiros.

Do exposto, resta comprovado que a questão aqui analisada abrange todo o país, do Oiapoque ao Chuí. No extremo norte do Brasil a experiência está em andamento com tendência a aumentar sua escala em nível local. 


\title{
A IMPLANTAÇÃO DE ESCOLAS CIVIS DE GESTÃO MILITAR NO ESTADO DO AMAPÁ: CARACTERÍSTICAS INSTITUCIONAIS DO MODELO LOCAL
}

No Amapá, a implantação da gestão de ensino militar em escolas públicas civis iniciou-se, segundo Rodrigues e Lopes (2019) no ano de 2017, e hoje conta com três unidades: duas na capital Macapá e uma no município de Santana.

A iniciativa partiu da Secretaria de Estado da Educação, que propôs às corporações militares a parceria, cujo objetivo é

\begin{abstract}
Contribuir com (sic)o desenvolvimento de um ambiente que cultive a disciplina, o respeito à hierarquia, a meritocracia, a ética, responsabilidades, a promoção de um ambiente organizado e acolhedor, voltado para a melhoria do aprendizado do aluno e para o benefício da comunidade. (RODRIGUES E LOPES, 2019, p.325)
\end{abstract}

No extremo norte do Brasil, os militares que são destacados para o exercício em unidades escolares civis públicas recebem gratificação específica somada aos salários para desenvolver essas funções.

As três unidades escolares escolhidas atendem aos critérios de vulnerabilidade social, localização periférica, e também neste caso, rotatividade/ alternância de gestores em função de problemas específicos que se apresentam em escolas de periferia.

Uma questão importante no caso amapaense é a divulgação da ideia de que a gestão dessas escolas militarizadas é realizada de forma compartilhada ${ }^{4}$; no entanto, "A gestão da escola militar é centralizada, pois os militares possuem autonomia para tomar suas decisões sem a interferência da SEED 5 ." (RODRIGUES; LOPES, 2019, p.328).

Uma das escolas que implantou o novo modelo no Amapá foi particularmente visitada, observada e pesquisada pelos autores deste trabalho. Durante duas semanas foram realizadas as visitas, observações e conversas informais com monitores e gestores militares da unidade escolar. Entrevista foi realizada com o Diretor Adjunto, militar cuja patente é de Tenente. Perguntado sobre a denominação "escola militar", ele explicou que o termo é incorreto, visto que a gestão não seria totalmente militar, porque a unidade está sob a gestão maior da Secretaria de Educação, sendo considerada como civil, mas

\footnotetext{
$4 \quad$ No estado do Amapá, a nomenclatura que o governo estadual vem utilizando para o novo modelo é Gestão Escolar Compartilhada.

$5 \quad$ Secretaria de Estado da Educação do Amapá.
} 
segundo ele, a pretensão era que apenas os militares ficassem na gestão e na operacionalização de todas as demais atividades da escola. A resposta, no fundo, omitiu a centralização das decisões pelos militares. Embora a unidade esteja no organograma da Secretaria de Educação, esta transferiu toda a responsabilidade para a PM.

No Amapá, podem-se inferir algumas evidências reveladoras: 1) a propaganda do governo estadual é de que a gestão é compartilhada, mas, de fato, ela é centralizada, exclusivamente, nos militares, embora o pleito deles seja por um típico colégio militar, que inexiste nessa unidade da federação; 2) os militares não ficam completamente à vontade com a presença dos civis (que podem reivindicar participações nas decisões), seja no âmbito da gestão institucional da unidade escolar ou mesmo da gestão pedagógica, especificamente; 3) os civis, professores e coordenadores pedagógicos estão realmente "enquadrados" na filosofia de educação militar e ficam restritos às suas funções instrumentais sem grandes questionamentos, salvo exceções ocasionais.

Nossos achados revelam que a escola pesquisada teve que passar por reformas, pois as condições estruturais eram precárias. De acordo com as conversas informais, foi realizada força tarefa por parte do corpo militar e vários serviços foram realizados previamente. $\mathrm{Na}$ observação in loco, chamou nossa atenção que a estrutura física da escola havia sido renovada, a escola possuía cadeiras e carteiras novas e recursos financeiros tinham sido aportados ao caixa escolar ${ }^{6}$. Com isso, foi possível realizar a limpeza e manutenção das centrais de ar condicionado, que estavam funcionando plenamente; a quadra encontrava-se reformada e pintada, banheiros e cantina limpos em estado de "novos", instalações elétricas e hidráulicas funcionando satisfatoriamente.

O projeto de implantação da escola militar em escolas civis, conforme os relatos do entrevistado e dos monitores militares ${ }^{7}$, assim como da mídia televisiva local, passou por várias etapas, como: pesquisa de local propício ao novo modelo, análise técnica sobre como introduzir e mesclar a filosofia militar aos moldes da base nacional curricular de educação, a sensibilidade e o diálogo com a comunidade através de reuniões e audiências públicas com os pais e com sindicatos, para, ao final, obter a aprovação por quase toda a comunidade.

A entrevista revelou que a escolha dos policiais designados para trabalhar na instituição de ensino seguiu um critério específico: deveriam ser habilitados em cursos de licenciaturas. Assim, além de destacar para a unidade de ensino policiais

\footnotetext{
6 No Amapá, caixa escolar é a conhecida unidade executora que recebe recursos públicos para suprir necessidades de rotina da escola.

$7 \quad$ O papel dos monitores militares é central no controle da disciplina e na implementação dos códigos de condutas militares na escola.
} 
formados na área de educação os gestores militares pensaram na possibilidade das ausências pelos professores civis, ocasião em que os militares monitores poderiam assumir as turmas de alunos, ensinando as noções de valores morais, civismo, ordem unida, temas sobre drogas, trânsito, além de temas transversais. Nas visitas realizadas, observou-se que, normalmente, os monitores ficavam pelos corredores, garantindo que os alunos estivessem em sala de aula, sem a ocorrência de qualquer "balbúrdia".

Segundo o gestor militar entrevistado, o objetivo da gestão militar compartilhada em escolas civis é criar um ambiente saudável, sadio e propício para que o aluno tenha todas as possibilidades de obter e compartilhar conhecimentos. Os militares têm particular preocupação com temas como: ética, cidadania e respeito ao próximo, junto com várias ações civis que devem ser trabalhadas durante o período letivo.

Sobre a rotina (o ritual) implementada pelos militares, a equação pode ser compreendida pela sequência 'comando - resposta - reforço do comando assimilação - reforço - acomodação'. Esse método era amplamente utilizado nos modelos de internato que Émile Durkheim exemplificou como melhor modelo para inserir a cooperação coletiva, em um esquema de subordinação e reforço. A padronização dos alunos foi aspecto evidente, desde o uso de uniformes (blusa, calça jeans e sapato fechado ou tênis), regras quanto ao cabelo (as meninas deveriam prendê-los tipo coque e os meninos deveriam manter o cabelo curto no estilo militar).

A dinâmica das atividades rotineiras na escola correspondia aos horários matutino e vespertino, em que, todos os dias, os monitores reuniam os alunos na quadra, em fila, para gerar relatórios e instituir o clima de escola militar, e lá faziam as anotações quanto às faltas e abordavam as canções, brados de guerras e davam as orientações diárias. Após esse momento, os alunos eram deslocados à sala de aula, pelotão por pelotão (pelotão = turma), onde os professores aguardam em sala e o aluno do dia ou o "chefe de turma" pedia ao professor a permissão para o pelotão entrar na sala de aula.

Os alunos que chegavam atrasados eram separados na quadra, para que os monitores anotassem seus nomes e retirassem ponto do aluno. Isto porque todos os alunos têm uma pontuação por "bom comportamento", começando a partir da nota 8 , que pode ser acrescida até 10 , de acordo com o nível comportamental e com o modo de se portar do aluno no ambiente escolar. E mais, eram atribuídos cargos aos alunos, como é o caso do "chefe de turma" e o "aluno do dia", com o intuito de criar neles responsabilidades e as noções de meritocracia. 
Quanto às responsabilidades observamos que a limpeza da sala pelos alunos, após o término da aula, é uma das tarefas. Todo dia ficavam de 3 a 5 alunos/as, de acordo com a ordem da chamada, para realizar o trabalho. Além da sala de aula, os gestores militares exigiam que qualquer local que fosse utilizado pelos alunos/as deveriam ser limpos após seu uso, garantindo, assim, uma melhor organização do espaço escolar, segundo a gestão. De acordo com a entrevista, essas responsabilidades reforçam a ideia de solidariedade, pois, para os militares, a cobrança dessas tarefas é não somente justa como também criaria nos alunos preocupação com o ambiente escolar, que é de todos. Rotineiramente, há um horário reservado para a ordem unida, onde são ensinados atividades civis, por exemplo: hastear a bandeira; cantar o hino nacional, treinar as posições (esquerda volver, direita volver, descansar, etc.) propiciando o reconhecimento das ordens militares, entre outros.

Semelhante a uma corporação militar, cada turma tem um codinome e passaram a ser identificadas como Batalhão. Nesse sentido, a ideia é formar uma fraternidade e cada batalhão tem um "grito de guerra" reforçando o ideal e os valores de cada equipe.

$\mathrm{Na}$ questão meritocrática, os pontos sobre comportamentos e condutas dos alunos/as somam-se às notas dos componentes curriculares. O resultado permite que os alunos com as melhores pontuações sejam presenteados nas formaturas ou eventos que acontecem na escola: por exemplo, quem serão os "alunos oficiais", os "alunos sargentos", e assim por diante, cada um exercendo um cargo mais importante ou não, conforme seus méritos.

\section{PRESSUPOSTOS TEÓRICOS DE UMA EDUCAÇÃO NEOCONSERVADORA: O POSITIVISMO E SUA RELAÇÃO COM A GESTÃO ESCOLAR CIVIL MILITARIZADA}

A educação de viés neoconservador das escolas públicas civis de gestão militar pode ser associada, teoricamente, à corrente filosófica positivista de ensino.

Os ideais positivistas surgiram desde o século XIX, na França, tendo como principal idealizador, Augusto Comte (1798-1857). No Brasil, as concepções positivistas encontraram guarida no período da consolidação da República, através principalmente de Benjamin Constant. Martins e Silva (2017) destacam alguns pontos chave do Positivismo que se fundamentam no conceito de que o conhecimento válido é aquele que pode ser provado cientificamente, excluindo, com isso, todas as outras formas construídas socialmente, em especial conhecimentos assistemáticos de matrizes populares. 
Além disso, os ideais da educação positivista, conforme Martins e Silva (2017), estão fortemente marcados pelos valores morais, de acordo com as tradições familiares, valorizando a ordem como meio de manutenção social.

A influência ideológica do positivismo na educação esmaeceu com o passar dos anos e com a chegada do neoliberalismo, todavia, ela sempre reverberou em segmentos conservadores brasileiros, que tendem a responsabilizar os paradigmas de uma educação progressista, responsáveis pelo "afrouxamento" da disciplina em sala de aula e pelos maus resultados escolares do sistema público de ensino nacional, nos últimos tempos.

Émile Durkheim (2008; 2011), é sem dúvidas, o teórico chave que pode ajudar na explicação que leva pessoas a se apegarem a um modelo de sociedade mais coeso que teria capacidade de manter a ordem social. Para ele, a escola serve como mecanismo de manutenção da ordem social, onde os alunos deveriam aprender como "se portar" em sociedade. A clássica definição de Durkheim (2011, p. 53-54) é sempre reveladora

A educação é a ação exercida pelas gerações adultas sobre aquelas que ainda não estão maturas para a vida social. Ela tem como objetivo suscitar e desenvolver na criança um certo número de estados físicos, intelectuais e morais exigidos tanto pelo conjunto da sociedade política quanto pelo meio específico ao qual ela está destinada em particular.

Segundo Souza e Campos (2016, p .13), Durkheim defendia a ideia de que

A harmonia de uma sociedade seria decorrência direta do reconhecimento e acato, por parte de seus integrantes, do conjunto de normas, opiniões coletivas, hábitos, leis, linguagens, dentre outros elementos que constituem a cultura de um determinado grupo social.

Em A Educação Moral, Durkheim (2008) assevera que a moral é um sistema de regras que predeterminam a conduta; elas dizem como devemos agir em cada situação e que devemos agir bem porque agir bem é obedecer bem. Foi sob essa perspectiva teórica que escolas públicas civis foram entregues nas mãos de órgãos estatais que defendem a obediência, a sujeição dos in0divíduos e que prioriza a meritocracia, mas, paradoxalmente, provoca a exclusão social com a (in) consequente divisão social do trabalho nos termos da sociedade capitalista em que vivemos. 
Souza e Campos (2016) salientam também que Durkheim, sendo um funcionalista, considerava existir "naturalmente" uma divisão social, portanto, em dois grupos de homens: 1) os homens de sensibilidade, que são tidos como aqueles que planejam, criam e pensam ações úteis para a evolução social, e 2) os homens de ação que executam as atividades pensadas pelo grupo anterior. Obviamente, que forma de organização social se divide entre aqueles que mandam e aqueles que obedecem, exatamente um formato que muito agrada as corporações militares.

Souza e Campos (2016, p. 16) ainda destacam que "A concepção apresentada por Durkheim acaba por naturalizar, consensualmente, as desigualdades decorrentes da lógica da divisão do trabalho na sociedade capitalista."

Do que percebemos na pesquisa empírica, os gestores militares não estão preocupados imediatamente com os problemas da desigualdade social. Para eles, esse não é um problema da escola, é um problema do sistema. Desse modo, sem dúvidas, uma escola que assim pensa, é reprodutora de todo tipo de desigualdades, tidos, para ela, como uma dimensão natural da sociedade maior em que vivemos.

Durkheim (2011) ainda advogou que a educação atua exteriormente ao indivíduo, de forma coercitiva e regulando socialmente a ordem, critérios estes que tornariam o ensino um fato social. Em decorrência, Souza e Campos (2016, p. 17) enfatizam que na teoria durkheimiana, "a escola, como consequência, se organiza em meio a conceitos e critérios como: arbitrariedade, respeito, controle, imposição, limite, rigor, ordem, consenso, moral e disciplina." Ou seja, tudo em conformidade com a novidade implementada no sistema educacional público civil brasileiro, fenômeno ligado à onda neoconservadora que pretende varrer o Brasil.

Do que restou comprovado dos pressupostos teóricos positivistas, inspiradores de uma pedagogia militar, não temos dúvidas de que tal pedagogia não permite a formação de um cidadão crítico e questionador. Estes atributos não estão entre as competências a serem adquiridas por uma pedagogia durkheimiana. Isto é, as matrizes teórico-metodológicas e, portanto, pedagógicas primam por um ser humano que se adapte de bom grado à sociedade em que vive, mesmo que ela seja desigual e que existam boas razões para criticá-la.

Por último, e ainda lembrando o Pai da Sociologia, Paugam (2017, p. 142) continua esclarecendo a posição de Durkheim no debate indivíduo-sociedade,

Nos textos de Durkheim é frequente a questão da sociedade em geral como se fosse apenas uma, encontra-se justamente em $A$ Educação Moral uma análise da multiplicidade de pertencimentos. Durkheim retém, principalmente, três tipos de pertencimento: a família, a pátria e a humanidade. 
Nota-se claramente a preferência durkheimiana por uma sociedade conservadora, fundada primordialmente nas instituições Família, Pátria e Humanidade revelando, assim, sua preocupação com elementos que poderiam causar distúrbios funcionais na coesão social. Trata-se, sem sombra de dúvidas, de uma visão de mundo que ampara e fundamenta os princípios do "novo" modelo de gestão de escolas civis públicas militares, que ficou conhecido no estado do Amapá como Gestão Escolar Compartilhada que, de compartilhada nada tem.

\section{CONSIDERAÇÕES FINAIS}

As evidências revelaram que o aceite e o apelo social para a implantação da gestão militar em escolas civis públicas deu-se em decorrência de alguns fatores, como: 1) a violência urbana no entorno, e mesmo dentro, das escolas, especialmente as de periferia; 2) com a colaboração da mídia, a crença pelas famílias de que os militares garantirão a segurança dos alunos, a ordem dentro do ambiente escolar e o controle dos comportamentos, evitando condutas ilícitas ou tidas como inadequadas pelos pais, como o uso de drogas e conflitos entre alunos; 3) a transferência pela Família da educação moral e cívica de seus filhos para os militares, uma vez que os pais, possivelmente, estão sentindo-se impotentes diante dos novos desafios do século XXI e porque a instituição Família foi reconfigurada hoje, noutras bases morais; 4) a esperança de que o modelo militar controlador e divulgador das noções de mérito possa tornar os alunos e as alunas mais estudiosos melhorando, assim, seus desempenhos escolares.

A reflexão teórica mostrou que a teoria pedagógica que explica os fundamentos de uma pedagogia militar é o Positivismo. Teoria que tem como alicerce a defesa da harmonia social, a divisão da sociedade entre os mais letrados e indivíduos executores onde os valores morais são um dos pilares principais.

$\mathrm{Na}$ pesquisa empírica, os achados comprovam uma rotina cujo ritual é, do ponto de vista pedagógico, a formação de alunos obedientes, disciplinados, treinados, inclusive, para uma educação corporal tida como corretiva. A meritocracia é o fundamento que explica o desempenho de cada um e uma preocupação institucional da escola. O rito ordinário na escola é para formar cidadãos passivos. No Amapá, isso ficou muito claro. Se o modelo vai conseguir formar esses indivíduos menos questionadores, não se sabe ao certo, pois em tempos de globalização e redes sociais as informações circulam de modo acelerado e (por que não dizer?) incontrolável.

À guisa de conclusão, portanto, a novidade do modelo aqui analisado só se sustenta do ponto de vista do arranjo institucional que transferiu a gestão da escola pública civil para militares, constituindo-se assim, um modelo híbrido. 
Do ponto de vista da Pedagogia não há qualquer novidade. Trata-se da velha e conhecida Pedagogia Bancária, que Paulo Freire tão bem revelou, uma pedagogia tradicional que retira do aluno o protagonismo que ele tem no processo ensino-aprendizagem. Estamos diante de uma curva que acirra/estimula o neoconservadorismo em andamento no Brasil. Os achados de campo, no caso do estado do Amapá, não deixam qualquer dúvida quanto a esta afirmação.

\section{REFERÊNCIAS}

BENEVIDES, Alessandra de Araújo; SOARES, Ricardo Brito. Diferencial de desempenho das escolas militares: bons alunos ou boa escola? UFC, 2015. Disponível em: <https://webcache.googleusercontent.com/search?q= cache:R8TpHu9q1jwJ:https://www.bnb.gov.br/documents/160445/960917/ DIFERENCIAL_DE_DESEMPENHO_DAS_ESCOLAS_MILITARES. pdf / 7ae9ef81-9687-46cb-b501-766ccef1 cba2 + \&cd = 1 \& hl = pt BR\&ct $=$ clnk\&gl $=$ br $>$ Acesso em: 15 abr. 2019.

CAMPOREZ, Patrik. Número de escolas públicas “militarizadas” no país cresce sob o pretexto de enquadrar os alunos. Revista Época. Goiânia, 02 ago. 2018. Disponível em: <https://epoca.globo.com/numero-de-escolas-publicasmilitarizadas-no-pais-cresce-sob-pretexto-de-enquadrar-os-alunos-22904768> Acesso em: 21 jul. 2019.

DURKHEIM, Émile. A Educação Moral. Vozes. Petrópolis. RJ. 2008.

Educação e Sociologia. Vozes. Petrópolis. RJ. 2011.

FERREIRA, Ana Rachel. Escolas cívico-militares: expansão de modelo divide opiniões. Nova Escola, 26 fev. 2019. Disponível em: <https://novaescola.org.br/ conteudo/15991/escolas-civico-militares-expansao-de-modelo-divide-opinioes> Acesso em: 30 jul. 2019.

GAZETA DO POVO. 02 ago. 2019. Escolas cívico-militares não podem exigir corte de cabelo, recomenda MPF. Disponível em: $<$ https://www.gazetadopovo.com.br/educacao/mpf-quer-proibir-padroesesteticos-em-escolas-civico-militares/> Acesso em: 10 ago. 2019. 
GOUVEIA, Marcelo. Colégios militares: uns querem, outros não. Entenda os porquês. Jornal Opção, edição 2090, 25 jul. 2015. Disponível em: <https:// www.jornalopcao.com.br/reportagens/colegios-militares-uns-querem-outrosnao-entenda-os-porques-41217/> Acesso em: 21 jul. 2019.

GUIMARÃES, Paula Cristina Pereira. Os novos modelos de gestão militarizadas nas escolas estaduais de Goiás. In: XXIX Simpósio Nacional de história. Rio de Janeiro, 2017. Disponível em: < https://www.snh2017.anpuh.org/resources/ anais/54/1502846486_ARQUIVO_TRABALHO_COMPLETO_ANPUH_Paula_2017(1).pdf> Acessado em: 26 ago. 2018.

GUIMARÃES, Paula Cristina Pereira; LAMOS, Rodrigo de Azevedo Cruz. Militarização das escolas da rede estadual de Goiás: a nova onda conservadora. Revista Pedagógica, Chapecó, v.20, n. 43, jan./abr. 2018. Disponível em: $<$ https://bell.unochapeco.edu.br/revistas/index.php/pedagogica/article/ view/4004> Acesso em: 21 jul. 2019.

LISBOA, Edgar. Escolas cívico-militares. Jornal do Comércio. Porto Alegre. Rio Grande do Sul. 01 ago. 2019. Disponível em < https://www.jornaldocomercio. com/_conteudo/colunas/reporter_brasilia/2019/08/696219-escolas-civicomilitares.html> Acesso em 10 ago. 2019.

MARTINS, Matheus Barbosa; SILVA, Edna Mara Ferreira da. A escola normal de campanha e a proposta de educação positivista de Benjamim Constant. In: IV Congresso Nacional de Educação (CONEDU), Minas Gerais, 2017. Disponível em: <https://editorarealize.com.br/revistas/conedu/trabalhos/ TRABALHO_EV073_MD1_SA4_ID9699_16102017231821.pdf> Acesso em: 28 jun. 2019.

PAUGAM, Serge. Durkheim e o vínculo aos grupos: uma teoria social inacabada. Sociologias: Porto Alegre, ano 19, n 44, jan./abr., 2017. Disponível em: $<$ http:/ /www.scielo.br/scielo.php?pid=S1517-45222017000100128\&script=sci abstract\&tlng=pt $>$ Acesso em: 23 jul. 2019.

PICARELLI, Maria. Militarização das escolas públicas: soldado ou cidadão? Revista Educação, no 257, 29 abr. 2019. Disponível em: <https://www. revistaeducacao.com.br/militarizacao-das-escolas/> Acesso em: 30 jul. 2019. 
REDAÇÃO RBA. MEC deve ampliar número de escolas militarizadas no Brasil. Rede Brasil Atual, 12 fev. 2019. Disponível em: <https://www. redebrasilatual.com.br/educacao/2019/02/mec-deve-ampliar-escolasmilitarizadas-criticadas-por-ferir-parametros-educacionais/> Acesso em: 21 jul. 2019.

RIO GRANDE DO SUL. Projeto de Lei $\mathbf{n} .72$ de 22 de fevereiro de 2019. Introduz modificações na Lei no 15.108, de 11 de janeiro de 2018, que dispõe sobre o Programa "Mais Efetivo" e dá outras providências, e na Lei no 11.991, de 27 de outubro de 2003, que cria o Programa de Militares Estaduais Temporários da Brigada Militar, e dá outras providências. Disponível em: <http://www.al.rs. gov.br/legislativo $/$ ExibeProposicao.aspx?SiglaTipo $=$ PL $\&$ NroProposicao $=72 \&$ AnoProposicao=2019\&Origem $=$ Dx $>$ Acesso em: 10 jul. 2019.

RODRIGUES, Efigênia das Neves Barbosa; LOPES, Josiane da Silva. Militarização das escolas da rede pública no município de Macapá: reflexões sobre a gestão militar compartilhada. In: Política e Gestão da Educação Básica I - Série Anais do XXIX Simpósio Brasileiro de Política e Administração da Educação, Organização: João Ferreira de Oliveira, e Daniela da Costa Britto Pereira Lima [Livro Eletrônico]. - Brasília: ANPAE, 2019.

SOUZA, Audrey Pietrobelli de; CAMPOS, Névio de. A concepção de educação de Émile Durkheim e suas interfaces com o ensino. Luminária, v. 18, n.02, 2016. Disponível em: < http://periodicos.unespar.edu.br/index.php/luminaria/article/ view/955/> Acesso em: 21 jul. 2019.

ADALBERTO CARVALHO RIBEIRO é Doutor em Ciências pelo Núcleo de Altos Estudos Amazônico/NAEA/UFPA. Realizou estágio de pós doutoramento no Insituto de Educação da Universidade de Lisboa/Portugal. Professor e pesquisador no Departamento de Educação da Universidade Federal do Amapá. E-mail: adalb.cr@gmail.com ORCID: http://orcid.org/0000-0002-5039-7179

PATRÍCIA SILVA RUBINI é Licenciada Plena em Pedagogia pela Universidade Federal do Amapá/UNIFAP.

E-mail: prubini444@unifap.br

ORCID: http://orcid.org/0000-0002-2491-7345 